\title{
A Probabilistic Assessment for Classification of Bridges Against Fire Hazard
}

Naser M.Z. ${ }^{1}$, Kodur V.K.R. ${ }^{2, *}$
Department of Civil and Environmental Engineering, Michigan State University, East Lansing, MI, USA

\begin{abstract}
This paper presents the development of a simplified approach for classification of bridges based on fire hazard. Statistical data from recent fires in bridges is utilized to quantify the probable risk of fire in bridges and also probability of fire-induced collapse of structural members in bridges. An importance factor is derived for identifying the vulnerability of bridges to fire hazard. The proposed importance factor, developed using weighted factor approach, takes into account the degree of vulnerability of different bridge components, critical nature of a bridge from traffic functionality point and fire mitigation strategies present in a specific bridge. The proposed importance factor for fire design, which is similar to the one currently used for evaluating wind, and snow loading in buildings, is validated against previous bridge fire incidents. It is shown through this validation that the proposed method for importance factor can be used as a practical tool for identifying critical bridges from the point of fire hazard.
\end{abstract}

Keywords: Fire hazard, Importance factor, Bridge collapse, Probabilistic risk, Fire resistance.

\subsection{INTRODUCTION}

Fire is considered to be one of the severe hazards that can significantly damage builtinfrastructure, including bridges, during their service life. In recent years, due to urbanization, ground shipping have increased demand on fuel transportation (flammable and combustible materials). Any collision of such fuel tankers near the vicinity of bridges can initiate huge fires.

\footnotetext{
${ }^{1}$ Ph.D. Candidate, Civil and Environmental Engineering, Michigan State University, Email: nasermoh@msu.edu

2,* Professor, Civil and Environmental Engineering, Michigan State University, Email: kodur@egr.msu.edu, Tel: 5173493167
} 
These bridge fires are characterized by high intensity fires with peak temperatures reaching as high as $1000^{\circ} \mathrm{C}$ within first few minutes of fire [1-5]. Such high intense fires, referred to as hydrocarbon fires, can cause significant economic and public losses. These losses include maintenance/reconstruction costs of fire induced minor/major/collapse of a bridge and costs of detouring traffic to nearby routes. In 2002, Battelle estimated bridge fire losses to be $\$ 1.28$ billion [6].

New York state department of transportation conducted a survey over a 15 year period (1990-2005) that shows fire-induced collapse in bridges to be three times higher than that due to earthquake events. However, in current practice, structural members in bridges are to be designed for earthquake loading but not for fire hazard [7]. In addition, Wardhaua and Hadipriono [8] as well as Scheer [9] showed that 3.2\% and 4.9\% of total bridge population experienced some level of collapse due to fire, respectively. Similarly, Kodur et al. $[1,10]$ reviewed recent bridge fire incidents and concluded that bridge fires can lead to major structural damage or collapse of bridges. However, no structural fire design provision for bridges currently exists in codes and standards.

There have been several bridge fire incidents in recent years. One such fire incident occurred at the I-20/I-59/I-65 interchange in Birmingham, AL, where on January 5, 2002 a gasoline fuel tanker carrying 37,000 liters of gasoline caught on fire. The bridge was made of $36.6 \mathrm{~m}$ long steel girders. The fire resulted in an intense heat producing temperatures in the range of $1100^{\circ} \mathrm{C}$. This rapid rise in steel temperature degraded strength and stiffness of steel girders causing them to sag 3 meters prior to collapse of the bridge [11]. After the fire incident, the bridge had to be shut down and commuters were detoured through nearby routes. Due to critical 
location of this bridge, the damaged bridge had to undergo inspection and rehabilitation process before re-opening for traffic which took 54 days [11].

Another fire broke out below the 9-mile road overpass at the I-75 expressway near Hazel Park, MI. This fire incident occurred on July 15, 2009, when a fuel tanker transporting 50,000 liters of flammable fuel crashed into a passing truck. This collision initiated severe burning with temperatures exceeding $1000^{\circ} \mathrm{C}$. These high temperatures resulted in degradation of strength and stiffness properties of the unprotected steel girders. Within 20 minutes of fire exposure, the overpass steel girders lost much of their capacity and collapsed. The collapse of these girders significantly affected traffic conditions in the region and also resulted in high costs for maintenance and repair [12].

From previous bridge fire incidents, it is clear that fire represents a significant hazard to bridges during their lifetime. However, occurrence of a fire on a bridge is still a rare event, and even in such cases, only few grow into larger size fires that can affect the structural members of a bridge. Thus, designing all bridges to withstand the adverse effects of fire may not be economical or practical. Only critical bridges, from the point of fire hazard, may have to be designed for fire safety. Identification of such critical bridges can be done through the use of fire-based importance factor similar to that used for evaluating snow or wind loading in the design of buildings [10].

This paper presents the development of weightage factor approach to derive an importance factor for fire design of bridges. In a previous study, Kodur and Naser proposed an importance factor for classification of bridge girders based on fire hazard [10]. The proposed importance factor considers only bridge girders to be vulnerable to fire, and does not take into 
consideration possible weakness of other super and sub-structural components of bridges to fire.

To overcome this limitation, the weighted factors approach is extended to derive an importance factor for super and sub-structural components (elements) such as, decks, abutments, girders and piers of a bridge taking into account different characteristics of these structural members. In addition, the revised importance factor accounts for the effect of "service features", such as gas pipelines and high-voltage transmission lines on fire hazard, as well as the impact of fire mitigation strategies in evaluating relative fire risk on a bridge.

\subsection{PROBABILISTIC RISK OF FIRE IN BRIDGES}

Fire incidents are random events that follow a stochastic (probabilistic) approach. The probabilistic nature of such events is best described as a series of independent events that occur over time. The nature of these events can be quantified using Poisson distribution. Poisson distribution has been used in previous studies to investigate probability of ignition and occurrence of fire incidents in buildings [13-17].

A review of literature was conducted on bridge fires to collect statistical data on number of bridge fires, fire causes, state of traffic at break out of fire, fire incident features (fire intensity, fuel type, duration of fire), bridge characteristics and overall bridge population. The literature review clearly indicate that there is a lack of reliable data on some of this information specific to bridge fires. For instance, only major fire incidents on bridges are well documented. Data related to traffic state and fire conditions vary significantly from one source to another. Even in cases where data on some parameters are available, there is a lack of mathematical (statistical) models to represent interaction of different parameters. For instance, no mathematical model to link fire severity, bridge characteristics and probability of fire induced 
collapse is yet available. Thus, it is clear that there is a need to develop mathematical (statistical) models that integrate these various parameters and better comprehend their complex relations.

However, based on the available statistical data, an estimate of fire to breaking out in a bridge and chances of inducing fire-induced collapse of structural members can be developed. This estimation is obtained with the aid of few assumptions. These assumptions simplify the aforementioned complex relation between various parameters, but uses reliable information on the number of fire incidents and associated fire losses. The approach used here utilizes similar set of assumptions as that used by other researchers to estimate probability of fires in buildings [1217].

According to National Fire Protection Association (NFPA) [18], there have been a total of 195,600 vehicle fire incidents that occurred on all U.S. roadways in 2011. Out of these fire incidents, 53,700 occurred on highways, 13,800 occurred on commercial roads and 22,500 burned on streets with the remaining incidents occurring on rural and residential driveways. As discussed earlier, and for the sake of this study, it is assumed that all vehicle fires have similar intensity [13-17]. Fire intensity measures the destructive impact of fire and is a function of fire temperature, type and availability of fuel, ventilation etc. This fire intensity can also be expressed as the mean of Poisson distribution $(\rho)$. Using the principles of Poisson distribution, the estimated fire intensity of highway vehicle fires reported by NFPA is equal to $\rho=\frac{53,700+13,800+22,500}{195,600}=0.46$ year $^{-1}$. Then, applying Poisson distribution principles, the probability $(P)$ of one vehicle fire occurring every year is estimated as: $P=1-e^{-\rho t}=1-e^{-0.46(1)}=0.37(37 \%)$, where $(t)$ is the number of years. 
Since there is no available statistical information on the total number of fire incidents on bridges, a reasonable fraction of the total highway fire incidents can be assumed to occur in the vicinity of bridges. Herein, $5 \%$ of total highway fire incidents is assumed to occur on/underneath bridges. Following the same approach described above, the probability of a fire breaking out on a bridge is $\quad 2.27 \%, \quad\left(\rho=\frac{0.05 \times(53,700+13,800+22,500)}{195,600}=0.023 \mathrm{year}^{-1}, \quad\right.$ and $\left.P=1-e^{-\rho t}=1-e^{-0.023(1)}=0.0227\right)$. According to NFPA 551 [19] provisions, a risk having a probability ranging between $0.1 \%$ and $10 \%$ is considered a probable risk. Probable risks are those which can occur several times during a life span of a system (50-75 years for highway bridges) [19]. Given the annual increase in number of vehicles, fuel shipping, and number of collisions, the roughly estimated probability of fire occurrence on a bridge seems realistic.

Further, Wardhana and Hadipriono [8] recently published statistical data on total number of highway bridges and number of collapsed bridges in the US over a period of 11 years (19892000). Wardhana and Hadipriono [8] reported that there are 691,060 highway bridges. In addition, they stated that total number of bridge failures due to different extreme loading events was 503; out of which 16 bridges collapsed due to fire. Following the same assumptions discussed above, the estimated probability of at least one bridge collapsing due to fire is $P=1-e^{-\rho t}=1-e^{-0.032(1)}=0.031(3.1 \%), \quad$ where; $\quad \rho=\frac{16}{503}=0.032$ year $^{-1} . \quad$ The estimated probability agrees with the findings of Wardhaua and Hadipriono (4.9\%) as well as Scheer $(3.2 \%)[8,9]$. Thus, the set of assumptions used in this study lie within the actual observations reported in previous surveys and studies. Using the same procedure outlined above, the probability of at least one bridge collapsing due to fire in a 10 and 50 year period is 27.3 and 
$79.8 \%$, respectively. This clearly show that there is a high probable risk of fire-induced collapse of a bridge in a 50 year period.

In order to compare magnitude of fire problem in bridges to that of buildings, Poisson distribution is applied to analyze fire incidents in buildings. In 2006, there were 118 million buildings in the US. In 2012, approximately 480,500 fire incidents occurred in buildings and about $1,375,000$ fire incidents has been reported in total [20]. Hence, the probability of a fire occurring in a building is $P=1-e^{-\rho t}=1-e^{-0.35(1)}=0.295$ (29.5\%), where $\rho=\frac{480,500}{1,375,000}=0.35$ year $^{-1}$, which is almost thirteen times higher than those to occur in bridges.

In 2002, National Institute for Standards and Technology (NIST) conducted a survey on fire-induced collapses of multi-story buildings in USA over a period of 32 years (1970-2002). The outcome of this survey showed that there were a total of 22 fire-induced building collapses in addition to 7 buildings that suffered severe structural damage due to fire and had to be demolished [21]. Although there is lack of reliable data on total number of buildings collapsed in 2002, Wardhaua and Hadipriono [8] reported that the total number of building failures (collapse) from various catastrophic events, including fire, is 225 . Hence, probability of fire-induced collapse of a building is $P=1-e^{-\rho t}=1-e^{-0.129(1)}=0.121(12.1 \%)$, where $\rho=\frac{22+7}{225}=0.129$ year $^{-1}$. It can be seen that probability of a building to collapse is four times higher than that of a bridge. Table 1 and Fig. 1 compare number of fire incidents and probability of collapse between bridges and buildings in USA.

The above statistical data clearly show that probability of fire occurring in a building, as well as fire induced collapse of a building, is much higher than that of bridges. In addition, US U.S. Department of Homeland Security and Eldukair and Ayyub estimated fire-based economic 
consequences of damage to residential buildings and bridges to be 7,199 and 959 million dollars, respectively $[22,23]$.

The consequences of fire hazard in buildings is recognized in current codes and standards and thus, structural members in buildings are to be designed for fire resistance requirements since occupant safety is of primary concern. On the other hand, no special requirements for fire safety in bridges is present in current codes and standards. This is due to the belief that occupants safety is not at greater risk as bridges are open structures, fire incidents in bridges involve less number of individuals and thus there is higher probability that any commuters can quickly evacuate to safety. However, recent fire incidents indicate that consequences of a fire on a bridge can produce devastating impact from the point of traffic flow and property damage. This can be overcome to some extent through the provisions of fire resistance features to structural members of critical bridges.

\subsection{APPROACH FOR CLASSIFICATION OF BRIDGES BASED ON FIRE RISK}

Although fire represents a significant hazard to bridges, it is of rare occurrence. In many fire incidents, fires burn-out quickly or are extinguished through firefighting before significant damage to structural members. As a result, it is not economical or practical to design all bridges for fire hazard. Only bridges that are at high risk from the point of fire hazard are to be designed for fire safety. In such bridges, fire hazard can be tackled, to a certain extent, through provision of appropriate fire resistance to structural members. The structural system in bridges comprise of super-structural members (slabs and decks) and sub-structural members (girders, piers and abutments). [1,2]. These structural members can be constructed of different materials and may be designed with specific characteristics. Thus, expected overall fire resistance of a bridge is a function of fire performance of both super and sub-structural members. In order to quantify fire 
risk and determine appropriate fire resistance measures, fire resistance of each member is to be evaluated. For this purpose, a fire-based importance factor, similar to that used for evaluating snow or wind loading in the design of buildings, can be used to classify fire risk associated with each structural member of the bridge.

The importance factor for assessing fire risk in a bridge is a function of vulnerability of structural members to resist fire and also resulting consequences of a fire incident on traffic flow. The degree of vulnerability of super and sub-structural components to fire mainly depends on fire resistance of various structural members of bridges. The impact of fire on a bridge is dependent on the critical nature of the bridge from the point of traffic functionality.

\section{Vulnerability of a bridge to fire}

The vulnerability of a bridge to fire hazard is mainly a function of performance of structural members under fire conditions. The factors that influence fire performance of structural members include geometrical features, materials used in construction, loading and restraint conditions and fire intensity. For instance, sectional geometry and member detailing can significantly enhance fire resistance of structural members i.e. members with larger steel sections exhibit higher fire resistance than those with smaller sections. Similarly, increasing concrete cover to steel rebars enhance fire resistance of reinforced concrete members. In addition, the thermo-physical and mechanical properties of constituent materials (concrete, steel, wood) significantly affect fire resistance of structural members. All materials experience loss of strength and stiffness properties at high temperatures. However, rate of loss vary depending on the composition of constituent materials. Structural members made of steel experience much faster degradation in strength than that of concrete members. The type and intensity of loading, as well as restraint conditions, can significantly influence the fire performance of structural 
members. Typically, high load levels subject the members to additional stresses; hence available capacity can degrade at much faster rate in a fire. Restrained support conditions can significantly enhance fire resistance of flexural members due to development of fire induced restraint forces that can counter balance the load induced moments. Finally, fire severity in a bridge and its duration depend on the available fuel type and quantity. Presence of highly flammable hydrocarbon products, unlimited oxygen supply and lack of fire protection (or firefighting) measures can accelerate the rate of growth of fires, producing high intensity fires.

\section{Critical nature of a bridge}

Critical nature of the bridge is the second main factor that determines the importance of a bridge, from fire hazard point of view. This factor is mainly influenced by bridge location and traffic density. For instance, certain bridges that connect routes across natural obstacles (such as valleys or rivers) are the sole means of ground transportation between such obstacles, especially in railroad/train routes. Hence, any closure of such bridges due to fire damage will significantly slow down or shut-off the traffic in the region. Similarly, traffic density can determine the critical nature of the bridge. If a bridge is located on a major highway or in the vicinity of an urban area that serves large number of vehicles, prolonged loss of operation due to fire can lead to significant traffic disruptions in the region and affect large number of commuters.

\subsection{IMPORTANCE FACTOR FOR BRIDGES BASED ON FIRE RISK}

The previously developed fire-based importance factor for girders is expanded to cover all components of a bridge [10]. In addition, the revised importance factor accounts for additional features that influence fire performance of bridges. The importance factor for estimating fire risk is derived by applying a weighted factor approach where in due consideration is given to all factors influencing the fire performance of a bridge and also the consequences of 
fire. This importance factor takes into account vulnerability of bridge structural members to fire, as well as critical nature of the bridge to traffic flow.

\section{$\underline{4.1 \text { Methodology of the proposed approach }}$}

For deriving an importance factor, the key characteristics that influence fire hazard in bridges are grouped into five classes, namely, geometrical features, material properties and design characteristics, hazard (fire) likelihood, traffic demands, economic impact, and expected fire losses. Each class covers different parameters that contribute to the importance factor. Within each parameter, there are various sub-parameters that determine the conditions of a specific structural member in a bridge. The five classes, parameters, and sub-parameters are listed in Table 2. Based on engineering judgment and recommendations of previous studies [1, 2, $9,10,17-19,24,25]$ weightage factors are assigned to different sub-parameters. These weightage factors $\left(\varphi_{i, x}\right)$, are assigned on a scale of 1 to 5 based on the critical influence of that subparameter to fire performance of structural member or impact to fire, are shown in Table 2. Further information on the classes, parameters, sub-parameters and rationale for assigning weightage factors can be found in a previous study [10].

It should be noted that the newly added parameter 'Structural Component' specifically accounts for fire vulnerability of super and sub-structural components in a bridge i.e., deck, abutments, girders and piers. As discussed above, weightage factors $\left(\varphi_{i, x}\right)$, are assigned to each sub-parameter on a scale of 1 to 5 (in Table 2) based on the critical influence of that subparameter to fire performance of structural member, where the largest value (5) indicates the highest risk (susceptibility) to fire hazard. The rationale for assigning larger weightage factors in an ascending order for deck $\left(\varphi_{g, s c}=1\right)$, abutment $\left(\varphi_{g, s c}=2\right)$, girder $\left(\varphi_{g, s c}=3\right)$ and pier $\left(\varphi_{g, s c}=4\right)$ is due to the fact that fire can be much more concentrated around piers as compared to girders; 
since fires tend to break out following a collision of a fuel tanker with a pier/other vehicle in the vicinity of a bridge. In addition, damage or collapse of a pier can cause significant and immediate collapse to a fire-damaged bridge than damage/loss of deck, abutments or a girder as the extent of their exposed area to fire is localized compared to their overall span.

The weightage factor approach of evaluating importance factor comprises of four main steps. In the first step, knowing the maximum weightage factor for various parameters of a bridge (from Table 2 ), a class factor $\left(\psi_{x}\right)$ is calculated as:

$\psi_{x}=\frac{\sum \varphi_{x(\max )}}{\varphi_{\text {total }}}$

where,

$\varphi_{x(\max )}$ is the maximum weightage factor of each parameter in class $(x)$

$\varphi_{\text {total }}$ is the summation of maximum weightage factors of all parameters in all five classes

In step 2; a class coefficient $\left(\Delta_{x}\right)$ is calculated as the ratio of the summation of the weightage factors of all sub-parameters in class $(x)$ to the summation of the maximum weightage factor of all the parameters in the same class:

$\Delta_{x}=\frac{\sum \varphi_{i, x}}{\sum \varphi_{x(\max )}}$

where,

$\varphi_{i, x}$ is the weightage factor of sub-parameter $(i)$ in class $(x)$ 
$\varphi_{x(\max )}$ is the maximum weightage factor of each parameter in class $(x)$

In the third step, an overall class coefficient $(\lambda)$ is evaluated as the summation of the product of class coefficient $\left(\Delta_{x}\right)$ and corresponding class factor $\left(\psi_{x}\right)$ as shown in Eq. 3;

$$
\lambda=\sum \Delta_{x} \psi_{x}
$$

In the fourth step, the overall class coefficient $(\lambda)$ is utilized to assign fire risk grade for the structural member by comparing the value of the overall class coefficient $(\lambda)$ with an arbitrary numerical score provided in Table 3. Upon knowing the fire risk grade, an importance factor $(I F)$ can be arrived at. Table 3 shows the risk grades and related overall class coefficient ( $\lambda$ ) scores. The extent of contribution of each class to the importance factor is illustrated in Fig. 2.

In order to quantify importance factor for fire design of bridges, the outlined procedure is carried out for different structural components (super and sub-structural members). Once overall class coefficient $(\lambda)$ for different structural members is obtained, worst case scenario (highest importance factor) is assigned to the bridge. For instance, if estimated overall class coefficient ( $\lambda$ ) for girders and piers of a typical bridge is $0.47(I F=1.0)$ and $0.5(I F=1.2)$, respectively, then the overall importance factor for this bridge is 1.2 (based on the highest importance factor of $1.2)$.

It should be noted that the extended approach can also be applied for analyzing number of special cases such as elevated highway extensions, "overpasses" that connects highways to elevated ramps (which often lack need for abutments) or short-span bridges (constructed without piers). In these cases, fire importance factor for decks and girders would govern the design of 
these bridges. In general, the designer should be aware that separate evaluation of structural members may yield different outcomes. For example in a bridge with composite structural members, fire importance factor for steel girders can be higher than fire importance factor for concrete piers since steel loses strength and stiffness properties at a much rapid pace when compared to concrete. In such a situation, only vulnerable structural member may need to be designed with additional fire resistance provisions.

Fire mitigation strategies can be implemented to prevent or reduce fire hazard in a bridge. Such fire mitigation strategies can enhance fire performance of bridges and reduce the adverse effect of fire. These measures are usually planned in the design stage of a bridge or implemented after structural review/survey during regular maintenance. Effect of fire mitigation strategies, on fire risk in a bridge, can be quantified by re-evaluating importance factor. This re-evaluation leads to reduce the value of fire-based importance factor. Such reduction in the value of importance factor is a function of number and type of implemented fire mitigation strategies in the bridge.

The common fire mitigation features that can be implemented in bridges is added through class VI. The different fire mitigation strategies are grouped under three main parameters namely, security, laws and regulation, and fire protection and insulation features (as shown in Table 4). Each of these parameters contains several sub-parameters with assigned weightage factors (on a scale of 1-5) as shown in Table 4. Examples of these strategies are presence of security guards and trained personnel, monitoring systems, limits on cargo size and operating time, availability of on-site fire equipment/foam deluge systems, use of fire rated insulation material (on main load carrying structural members) and design of structural components according to structural fire design principles. 
In order to evaluate the positive impact of fire mitigation strategies on fire importance factor, a fifth step of calculations is to be carried out. In this $5^{\text {th }}$ step, the product of fire mitigation strategies class coefficient $\left(\Delta_{f m s}\right)$ and corresponding class factor $\left(\psi_{\text {fms }}=18 \%\right)$ is subtracted from the overall class coefficient $(\lambda)$ of classes I-V as shown in Eq. 4. Then, the updated overall class coefficient $\left(\lambda_{u}\right)$ is compared against numerical scores in Table 3 to arrive at updated importance factor. The various steps associated with the evaluation of fire-based importance factor is illustrated through a flow chart in Fig. 3.

$$
\lambda_{u}=\lambda-\Delta_{f m s} \psi_{f m s}
$$

The above discussed fire mitigation strategies can be implemented to enhance fire performance of bridges that are classified under "high" or "critical" fire risk grade. These strategies will lower fire risk and minimize the impact of fire hazard on a bridge and this is reflected through reduced overall class coefficient $\left(\lambda_{u}\right)$, importance factor and associated risk grade. For example, if a bridge is classified under "high" fire risk grade $(I F=1.2)$, it is possible to reduce this fire risk grade to "medium" $(I F=1.0)$ by utilizing proper fire mitigation strategies such as these presented in Table 4.

In addition, impact of fire on bridges in terms of structural damage, traffic disruption (loss of operation) and human casualties is quantified herein. Table 5 lists a detailed description of impact of fire and recommended fire resistance requirement for the different fire risk category. For instance, major fire incident to occur on bridges classified under "high" risk grade are expected to cause significant damage to structural members of bridge (partial/complete collapse) as well as partial shutdown of operation with possible human injuries/losses. Thus, it is 
recommended that main structural elements of these bridges to have at least one hour fire proofing.

\subsection{VALIDATION OF THE PROPOSED APPROACH}

The above developed approach is validated by evaluating importance factor of several bridges that experienced major fire incidents. Detailed description of fire incidents at Bill Williams River Bridge, AZ, and at Wiehltalbrücke Bridge, Germany, and calculation of fire importance factor for fire incidents is discussed here.

In Parker, AZ, a fuel tanker crossing the Bill Williams River Bridge over-turned initiating a huge fire on July 28, 2006. This bridge, built in 1967, was made of prestressed concrete girders and a composite concrete deck. The fourteen precast AASHTO Type III concrete girders were of 23.3 meter span with a $165 \mathrm{~mm}$ cast-in-place concrete deck. Once the fuel tanker over-turned, the diesel fuel of about 29,000 liters in the truck, spilled and lead to a rapid burning. Although the fire burned for two and a half hours and affected three spans (8,9 and 10) of the bridge, much of diesel fuel reached the underside of the bridge through the deck drains, thus reducing the fire intensity. Post fire inspection has shown significant spalling in top and bottom flanges of girders of span 9. Further, localized spalling was also noticed in girders of spans 8 and 10. During post fire inspection, traffic had to be detoured to nearby routes. After inspection and necessary repairs, the bridge was re-opened to traffic. The total cost of retrofitting the bridge was about $\$ 700,000[18]$.

The above developed approach is applied to evaluate importance factor for this bridge against possible fire hazard. Based on the available data for this bridge, the various parameters and sub-parameters needed for assessing the importance factor were collected. Then, different 
steps discussed above were applied to evaluate importance factor. The "overall class coefficient" for this bridge was found to be 0.54 , and thus the "importance factor" for this bridge works out to be 1.2, which places the bridge under "high" risk grade. Since the bridge falls under "high" risk category, implementing some of the proposed fire mitigation strategies would enhance the fire performance of the bridge. For instance, implementing use of monitoring systems, limiting transport size to 20,000 liters and use of flooding agents and/or foam deluge systems, then the updated overall class coefficient $\left(\lambda_{u}\right)$ for girders and piers reduces to 0.46 and 0.47 , respectively. This will bring down the importance factor to 1. Thus, Bill Williams River Bridge would fall under "medium" fire risk category. It should be noted that detailed calculation of importance factor for this bridge is shown in the Appendix.

As part of second validation, a major fire incident that occurred at the Wiehltalbrücke Bridge, Germany on August 26, 2004 is analyzed. This steel girder bridge was constructed on 1971 with a span of $705 \mathrm{~m}$. The Wiehltalbrücke Bridge has a highest point elevated to $60 \mathrm{~m}$ above soil ground. This steel girders bridge rests on reinforced concrete columns. The fire occurred when a car collided with a fuel tanker transporting 33,000 litters of fuel. Upon the crash, the fuel tanker broke through a guardrail, fell-off of the bridge and exploded. The explosion killed the driver and initiated massive fire under the bridge. Temperatures arising from fire caused significant damage to steel girders of the bridge. Post fire inspection indicated that a $20 \mathrm{~m} \times 31 \mathrm{~m}$ girder segment needed to be replaced. Following the fire accident, the bridge had to be closed for weeks for full inspection and repair. This fire incident costed $\$ 9.8$ (€7.2) million, the most expensive traffic accident in German history [27].

The proposed approach was applied to evaluate the fire base importance factor and associated fire risk of this bridge. Data on various characteristics of the bridge was collected and 
weightage factor were assigned. Then, the overall class coefficient $(\lambda)$ was evaluated to be 0.59 , $0.61,0.68$ and 0.64 for deck, abutment, girders and piers, respectively. The steel girders of this bridge, as expected, are the most vulnerable structural members to fire. Thus, the bridge falls under "high" risk category with an importance factor of 1.2. In order to improve the fire risk state of the Wiehltalbrücke Bridge and reduce its fire risk class from "high" to "medium", fire mitigation strategies can be employed. Implementing a combination of proposed fire mitigation strategies (such as providing fire insulation to bridge girders and implementing structural fire design for main structural members of this bridge) would reduce fire risk of this bridge. By taking into account the fire mitigation strategies, the revised overall class coefficient $\left(\lambda_{u}\right)$ works out to be 0.5 with an importance factor of 1.0 and associated fire risk grade of "medium".

\section{$\underline{5.1 \text { Strategies for mitigating fire risk in bridges }}$}

The proposed importance factor can be applied for evaluating relative fire risk associated in bridges at design stage or prior to rehabilitation of an existing bridge. This rehabilitation process could be due to scheduled maintenance, upgrading state of bridge to meet current code provisions, or retrofitting after an adverse event.

The vulnerability of a bridge to fire can be assessed through the proposed fire-based importance factor. If the bridge is found to be in "critical" or "high" risk category, the vulnerability of the bridge to fire hazard can be minimized by providing some level of fire protection to structural members. In the case of concrete bridges, 1 to 2 hour of fire rating to structural members can be achieved through the provision of sufficient concrete cover thickness. Hence, no external fire protection may be needed for conventional concrete members. However, in the case of steel and timber bridges, external fire proofing to structural members may be needed to achieve desired fire ratings. In bridges with composite constructions, adequate fire 
resistance in structural members can be achieved through the utilization of composite action and also proper detailing of members.

The required fire protection to bridge structural members can be arrived at based on conventional prescriptive approaches (fire rating) or performance based design methods. The prescriptive approaches generally utilize tabulated fire ratings published in directories and standards. However, most of these fire ratings are based on fire tests conducted under ASTM E119 or ISO834 standard fire scenarios. These fire scenarios represent cellulosic-type fuel fires which occur in buildings. In the case of bridge fires, which occur due to burning of hydrocarbon products and in an open environment, these fires are much more intense. Bridge fires are generally represented by hydrocarbon fire scenarios $[1,2]$. Hence, the use of fire ratings based on prescriptive approaches and derived from ASTM E119 or ISO834 standard fires may not be appropriate for bridge structural members. For instance, 1 hour rating based on ASTM E119 may be equivalent to less than 1 hour exposure under hydrocarbon or RWS fire exposure. On the other hand, implementation of performance based design methods can provide designers with state-of-the-art solutions that are efficient, optimum and economical. Performance based design methods use rationale and engineering principles to arrive at unique solutions for bridges prone to high fire risk.

In the case of high risk bridges near urban centers, additional strategies such as establishing a fire station or other security measures closer to the location of these bridges can minimize vulnerability of such bridges from fire hazard risk. Through these fire stations, response time to reach fire incident site can be reduced. Also, flow of fuel tankers on critical bridges can be regulated. For instance, limiting number of fuel tankers that travel across a critical bridge to certain times and weather conditions. 


\subsection{DESIGN IMPLICATIONS}

The proposed fire based importance factor can be applied to assess vulnerability of different structural components of a given bridge or the overall bridge to fire hazard. This study marks the first step for developing a fire based importance factor that is similar to the importance factor used for wind design. This updated approach for importance factor also accounts for fire mitigation strategies that are adopted for enhancing fire performance of bridges. In addition, the proposed importance factor can be used to assess relative fire risk in existing or new bridges.

Based on importance factor calculations, if a bridge falls under "critical" or "high" risk category, the vulnerability of such a bridge to fire hazard can be minimized by developing suitable strategies. Such strategies can be based on prescriptive based solutions or performance based design solutions [28- 30]. Prescriptive approaches include fire insulation to vulnerable structural members based on standardized tests or tabulated fire ratings. Alternatively, applying performance based fire design solutions can be developed by carrying of detailed analysis of vulnerable structural members of bridges and unique solutions can be implemented to enhance fire resistance.

\subsection{CONCLUSIONS}

Based on the presented information above, the following conclusions can be drawn.

- Fire represents a severe hazard to structural members in bridges and can induce significant damage, partial or full collapse of structural members in certain scenarios.

- The probability of fire breaking out in bridges is thirteen times lower than that in buildings, however, impact of such fire on bridges can be much more devastating due to lack of adequate fire protection features and firefighting measures in bridges. 
- The probability of fire induced collapse of a bridge (in the US) over 10 and 50 year period is estimated to be 27.3 and $79.8 \%$, respectively, which is much less than that in buildings.

- The fire-based importance factor is derived taking into account vulnerability of structural members to fire hazard, critical nature of the bridge from the point of traffic functionality and also presence of any fire mitigation strategies.

- The proposed importance factor can be used to quantify fire risk in existing and new bridges and provides guidance for designers to tackle the problem of fire in bridges.

\subsection{ACKNOWLEDGMENTS}

This material is based upon the work supported by the National Science Foundation under Grant number CMMI-1068621 to Michigan State University. Any opinions, findings, and conclusions or recommendations expressed in this paper are those of the authors and do not necessarily reflect the views of the sponsors.

\section{REFERENCES}

[1] V. Kodur, L. Gu, L., M. Garlock, Review and Assessment of Fire Hazard in Bridges, Transportation Research Record: Journal of the Transportation Research Board No. 2172: 23-29.

[2] M. Garlock, I. Paya-Zaforteza, V. Kodur, L. Gu, Fire hazard in bridges: Review, assessment and repair strategies, Engineering Structures 35 (2012) 89-98.

[3] D. Guthrie, V. Goodwill, M. Hicks, Tanker fire shuts down I-75, collapses Nine Mile bridge, The Detroit News (2009).

[4] Y. Bai, W. Burkett, P. Nash, Rapid Bridge Replacement under Emergency Situation: Case Study, J. Bridge Eng. 11 (2006) 266-273. 
[5] U.S. Department of Transportation, Federal Highway Administration, Highway Statistics, 1995-2010: Ibid., Highway Statistics (Washington, DC: Annual Issues), 2010.

[6] Battelle. Comparative risks of hazardous materials and non-hazardous materials truck shipment accidents/incidents. Washington D.C. (USA): Federal Motor Carrier Safety Administration; 2004.

[7] New York State Department of Transportation, Bridge Fire Incidents in New York State, New York State Department of Transportation, USA; 2008.

[8] K. Wardhana, F. Hadipriono, Study of recent building failures in the United States. Journal of perf. Of Const. Facilit. ASCE 17 (2003) 151-158.

[9] J. Scheer, Failed Bridges: Case Studies, Causes and Consequences, John Wiley \& Sons, 2010.

[10] V.K.R. Kodur, M.Z. Naser, Importance Factor for Design of Bridges Against Fire, Engineering Structures, 54 (2013) 207-220.

[11] T. Barkley, G., Strasburg, Bridge Rebuilt on the Fast Track, Public Roads Sept/Oct, FHWA, Vol. 66, 2002.

[12] D. Guthrie, V. Goodwill, M. Hicks, Tanker fire shuts down I-75, collapses Nine Mile bridge. The Detroit News, 2009.

[13] G. Ramachandran. Statistical methods in risk evaluation. Fire Saf J 80 (1979).

[14] R. Rutstein. The estimation of fire hazard in different occupancies. Fire Surv 1979.

[15] I. Rychlik, J. Ryde'n, Probability and risk analysis. An introduction for engineers. Berlin: Springer, 2006.

[16] J. Rahikainen, O. Keski-Rahkonen. Statistical determination of ignition frequencies of structural fires in different premises in Finland. Fire Technol (2004) 335-53. 
[17] J. Rydén, I. Rychlik, A note on estimation of intensities of fire ignitions with incomplete data, Fire Safety Journal, 41 (2006) 399-405.

[18] NFPA, U.S. vehicle fire trends and patterns. National Fire Protection Association, 1 Batterymarch Park, Quincy, MA 02169-7471, 2008.

[19] NFPA 551, Guide For The Evaluation Of Fire Risk Assessments, 2007.

[20] M. Karter. Fire loss in the United States during 2011. National Fire Protection Association, 2012.

[21] NIST GCR 02-843-1, Analysis of Needs and Existing Capabilities for Full-Scale Fire Resistance Testing, 2008.

[22] U.S. Fire Administration Fire Estimates, U.S. Department of Homeland Security • U.S. Fire Administration, National Fire Data Center, Emmitsburg, Maryland 21727

[23] A. Eldukair, B. Ayyub, Analysis of recent U.S. structural and construction failures, J. Perform. Constr. Facil. (1991) 57-73.

[24] K. Wardhana, F. Hadipriono, Analysis of Recent Bridge Failures in the United States, J. Perform. Constr. Facil., 17 (2003) 144-150.

[25] T. Elhag, Y. Wang. Risk assessment for bridge maintenance projects: neural network versus regression techniques, Journal of Computing in Civil Engineering, ASCE, (2007) 402-409.

[26] M. Davis, P. Tremel, A. Pedrego, Bill Williams river concrete bridge fire damage, Structural magazine, July 2008.

[27] H. Eisel, N. Palm, W. Prehn, G. Sedlacek, Brandschaden und Instandsetzung der Wiehltalbrücke im Zuge der A4, Köln - Olpe. Stahlbau, 2007. 
[28] NFPA 502 Standard for road tunnels, bridges, and other limited access highways, Quincy (MA), 2008.

[29] A. Esam, V.K.R. Kodur, An approach for evaluating the residual strength of fire exposed bridge girders, Journal of Constructional Steel Research, 88 (2013) 34-42.

[30] V.K.R. Kodur, A. Esam, and M. Dwaikat, Evaluating Fire Resistance of Steel Girders in Bridges. J. Bridge Eng., 18 (2013) 633-643. 


\section{APPENDIX}

Example illustrating calculations of importance factor for Bill Williams River Bridge, AZ. Step 1: Collect data and statistics on Bill Williams River Bridge

Step 2: Assign weightage factors ( $\varphi$ ) for different parameters (as in Table 2)

\section{Step 3: Calculate individual class coefficients $\left(\Delta_{x}\right)$}

The individual class coefficients $(\triangle)$ are computed as follows:

$$
\Delta_{x}=\frac{\sum \varphi_{i, x}}{\sum \varphi_{x(\max )}}
$$

where,

$\varphi_{i, x} \quad$ is the weightage factor of sub-parameter $(i)$ in class $(x)$

$\varphi_{x(\max )}$ is the maximum weightage factors of each parameter in class $(x)$

$$
\begin{aligned}
& \Delta_{g}=\frac{2+4+2+3+1+3+5+2}{5+4+5+4+3+4+5+5}=\frac{22}{35}=0.63 \\
& \Delta_{h}=\frac{3+1+1+4}{5+3+3+5}=\frac{9}{16}=0.56 \\
& \Delta_{t}=\frac{1+1}{5+3}=\frac{2}{8}=0.25 \\
& \Delta_{e}=\frac{1+1+1}{3+3+3}=\frac{3}{9}=0.33 \\
& \Delta_{f}=\frac{3+3}{3+3}=\frac{6}{6}=1.0
\end{aligned}
$$

\section{Step 4: Calcule of overall class coefficient $(\lambda)$}

The overall class coefficient $(\lambda)$ is given by:

$$
\begin{aligned}
& \lambda=\Delta_{g} \times \psi_{g}+\Delta_{h} \times \psi_{h}+\Delta_{t} \times \psi_{t}+\Delta_{e} \times \psi_{e}+\Delta_{f} \times \psi_{f} \\
& \lambda=0.63 \times 0.47+0.56 \times 0.22+0.25 \times 0.11+0.33 \times 0.12+1.0 \times 0.08=0.57
\end{aligned}
$$

Comparing $\lambda$ with values in Table 3 , risk grade for this bridge falls under "high" rsik category. Thus, the associated importance factor is 1.2. 


\section{Step 5: Calculate of updated Importance Factor (IF) to account for any fire mitigation strategies}

The above importance factor for this bridge can be re-evaluated when additional measures (such as implementing monitoring systems, limiting transport size to 20,000 liters and use of flooding agents and/or foam deluge systems) are adopted (as in Table 4) to minimized fire vulnerability;

$$
\begin{aligned}
& \Delta_{f m s}=\frac{1+4+2}{4+4+5}=\frac{7}{13}=0.54 \\
& \lambda_{u}=\lambda-\Delta_{f m s} \psi_{f m s} \\
& \lambda_{u}=0.57-0.54 \times 0.18=0.47
\end{aligned}
$$

Hence, the updated risk grade for the bridge is "medium" and associated importance factor is 1.0. 


\section{NOMENCLATURE LISTING}

$\begin{array}{ll}\rho & \text { Mean of Poisson's distribution } \\ P & \text { Probability of an event } \\ t & \text { Number of years } \\ \varphi & \text { Parameter weight } \\ \psi & \text { Class factor } \\ \psi_{g} & \text { Geometrical features, material properties and design characteristics class } \\ \psi_{h} & \text { factor } \\ \psi_{t} & \text { Hazard (fire) likelihood class factor } \\ \psi_{e} & \text { Traffic demand class factor } \\ \psi_{f} & \text { Economic impact class factor } \\ \psi_{f m s} & \text { Expected fire losses class factor } \\ \varphi_{x(\max )} & \text { Fire mitigation strategies class factor } \\ \varphi_{i, x} & \text { Maximum weightages factors of each parameter in class }(x) \\ \varphi_{t o t a l} & \text { Weightage factor of sub-parameter }(i) \text { in class }(x) \\ \Delta & \text { Summation of maximum weightages factors of all parameters } \\ \varphi_{i, x} & \text { Class coefficient } \\ \lambda & \text { Score value in an individual parameter of class }(x) \\ \lambda_{u} & \text { Overall class coefficient } \\ I F & \text { Updated overall class coefficient }\end{array}$




\section{LIST OF TABLES}

Table 1 Comparison of probability of fire incidents and fire-induced collapse in bridges and buildings

Table 2 Weightage factors based on the different features of a bridge.

Table 3 Risk grades and associated importance factors for fire design of bridges.

Table 4 Proposed fire mitigation strategies and assigned weightage factors

Table 5 Fire risk categories descriptions and recommendations 
Table 1 Comparison of probability of fire incidents and fire-induced collapse in bridges and buildings

\begin{tabular}{|c|c|c|}
\hline & \begin{tabular}{|c|} 
Bridges \\
2000
\end{tabular} & $\begin{array}{c}\text { Buildings } \\
\text { 2012 }^{*}, \mathbf{2 0 0 2}^{* *}\end{array}$ \\
\hline Total number of structures & 691,060 & $118,000,000$ \\
\hline Reported fire incidents & 4500 & 480,500 \\
\hline Probability of a fire breaking out (yearly) & $2.27 \%$ & $29.5 \%^{*}$ \\
\hline Number of collapsed structures & 503 & 225 \\
\hline Number of collapsed structures due to fire & 16 & 29 \\
\hline Probability of collapse due to fire (yearly) & $3.1 \%$ & $12.1 \%{ }^{* *}$ \\
\hline
\end{tabular}


Table 2 Weightage factors based on the different features of a bridge.

\begin{tabular}{|c|c|c|c|}
\hline \multicolumn{4}{|c|}{$\begin{array}{l}\text { Class I: Geometrical features, material properties and design characteristics }\left(\psi_{g}=\right. \\
0.47)\end{array}$} \\
\hline Parameter & Sub-parameter & $\begin{array}{c}\text { Weightage } \\
\text { factor }\left(\varphi_{g, x}\right)\end{array}$ & $\begin{array}{c}\text { Max. weightage } \\
\text { factor } \\
\left(\varphi_{g, x(\max )}\right)\end{array}$ \\
\hline \multirow{5}{*}{ 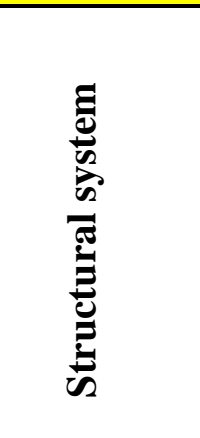 } & Truss/Arch & 1 & \multirow{5}{*}{5} \\
\hline & Girder - continuous & 2 & \\
\hline & Girder - simply supported & 3 & \\
\hline & Cable-stayed & 4 & \\
\hline & Suspension & 5 & \\
\hline \multirow{5}{*}{ 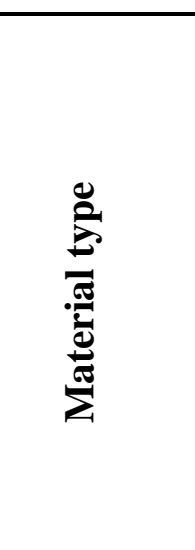 } & Reinforced concrete bridge & 1 & \multirow{5}{*}{5} \\
\hline & $\begin{array}{l}\text { High strength/(prestressed) } \\
\text { concrete bridge }\end{array}$ & 2 & \\
\hline & Steel-concrete composite bridge & 3 & \\
\hline & $\begin{array}{l}\text { Concrete bridge strengthened with } \\
\text { external FRP }\end{array}$ & 4 & \\
\hline & Steel and timber bridges & 5 & \\
\hline \multirow{4}{*}{$\begin{array}{l}\widehat{\Xi} \\
\text { है } \\
\text { ڤั }\end{array}$} & $<50$ & 1 & \multirow{4}{*}{4} \\
\hline & $50-200$ & 2 & \\
\hline & $200-500$ & 3 & \\
\hline & $>500$ & 4 & \\
\hline \multirow{3}{*}{ 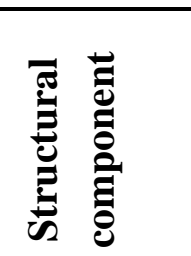 } & Deck & 1 & \multirow{3}{*}{4} \\
\hline & Abutment & 2 & \\
\hline & Girder & 3 & \\
\hline
\end{tabular}




\begin{tabular}{|c|c|c|c|}
\hline & Pier & 4 & \\
\hline \multirow{3}{*}{ 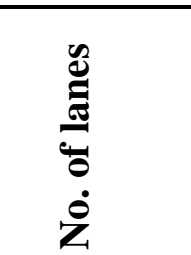 } & 2 & 1 & \multirow{3}{*}{3} \\
\hline & $2-4$ & 2 & \\
\hline & $>4$ & 3 & \\
\hline \multirow{4}{*}{ 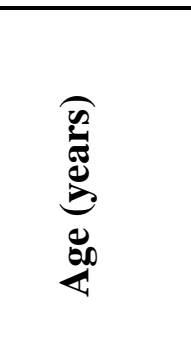 } & $<15$ & 1 & \multirow{4}{*}{4} \\
\hline & $15-29$ & 2 & \\
\hline & $30-50$ & 3 & \\
\hline & $>50$ & 4 & \\
\hline \multirow{5}{*}{ U } & 100 & 1 & \multirow{5}{*}{5} \\
\hline & $60-80$ & 2 & \\
\hline & $40-60$ & 3 & \\
\hline & $20-40$ & 4 & \\
\hline & $<20$ & 5 & \\
\hline \multirow{5}{*}{ 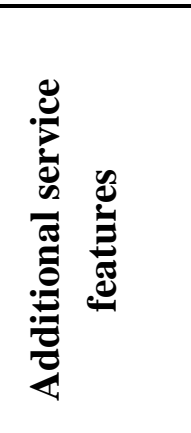 } & 1 deck & 1 & \multirow{5}{*}{5} \\
\hline & 2 decks + pedestrians & 2 & \\
\hline & Accommodates railroad & 3 & \\
\hline & Multi-level & 4 & \\
\hline & Above water & 5 & \\
\hline \multicolumn{4}{|c|}{ Class II: Hazard (fire) likelihood $\left(\psi_{h}=0.22\right)$} \\
\hline Parameter & Sub-parameter & $\begin{array}{c}\text { Weightage } \\
\text { factor }\left(\varphi_{h, x}\right)\end{array}$ & $\begin{array}{c}\text { Max. weightage } \\
\text { factor } \\
\left(\varphi_{h, x(\max )}\right)\end{array}$ \\
\hline \multirow{2}{*}{ 离 } & $<5$ & 1 & \multirow{2}{*}{5} \\
\hline & 5-10 & 2 & \\
\hline
\end{tabular}




\begin{tabular}{|c|c|c|c|}
\hline & $10-20$ & 3 & \\
\hline & $20-30$ & 4 & \\
\hline & $>30$ & 5 & \\
\hline 竞 & Conventional & 1 & \\
\hline స & Landmark & 2 & 3 \\
\hline 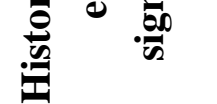 & Prestigious & 3 & \\
\hline & None (low) & 1 & \\
\hline $\bar{\varpi}$ & Not available (medium) & 2 & 3 \\
\hline$=$ & Frequent (high) & 3 & \\
\hline & $\begin{array}{l}\text { Natural causes/malfunction of } \\
\text { utilities control systems }\end{array}$ & 1 & \\
\hline & $\begin{array}{l}\text { A collision and fire with other } \\
\text { vehicles }\end{array}$ & 2 & \\
\hline$\stackrel{\varrho}{=}$ & $\begin{array}{l}\text { A fuel tanker collision and fire } \\
\text { with bridge sub-structure }\end{array}$ & 3 & 5 \\
\hline & $\begin{array}{l}\text { Major fuel tanker collision and } \\
\text { fire with multiple vehicles and } \\
\text { against bridge sub-structure }\end{array}$ & 4 & \\
\hline & $\begin{array}{l}\text { Fire due to fuel freight ship } \\
\text { collision with a bridge pier }\end{array}$ & 5 & \\
\hline & Class III: Traffic de & $\left(\psi_{t}=0.11\right)$ & \\
\hline Parameter & Sub-parameter & $\begin{array}{l}\text { Weightage } \\
\text { factor }\left(\varphi_{t, x}\right)\end{array}$ & $\begin{array}{c}\text { Max. weightage } \\
\text { factor } \\
\left(\varphi_{t, x(\max )}\right)\end{array}$ \\
\hline$=\overline{\bar{y}}=$ & $<1,000$ & 1 & 5 \\
\hline$\frac{2}{2}$ & $1,000-5,000$ & 2 & \\
\hline
\end{tabular}




\begin{tabular}{|c|c|c|c|}
\hline & $5,000-15,000$ & 3 & \\
\hline & $15,000-50,000$ & 4 & \\
\hline & $>50,000$ & 5 & \\
\hline \multirow{3}{*}{ 氖 } & Rural & 1 & \multirow{3}{*}{3} \\
\hline & Suburban & 2 & \\
\hline & Urban & 3 & \\
\hline \multicolumn{4}{|c|}{ Class IV: Economic impact $\left(\psi_{e}=0.12\right)$} \\
\hline Parameter & Sub-parameter & $\begin{array}{c}\text { Weightage } \\
\text { factor }\left(\varphi_{e, x}\right)\end{array}$ & $\begin{array}{c}\text { Max. weightage } \\
\text { factor } \\
\left(\varphi_{e, x(\max )}\right)\end{array}$ \\
\hline \multirow{3}{*}{ 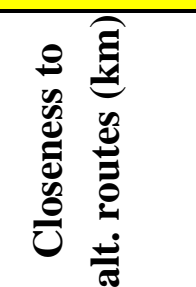 } & $<10$ & 1 & \multirow{3}{*}{3} \\
\hline & $10-20$ & 2 & \\
\hline & $>20$ & 3 & \\
\hline \multirow{3}{*}{ 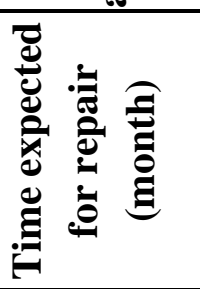 } & $<3$ & 1 & \multirow{3}{*}{3} \\
\hline & $3-9$ & 2 & \\
\hline & $>9$ & 3 & \\
\hline \multirow{3}{*}{ 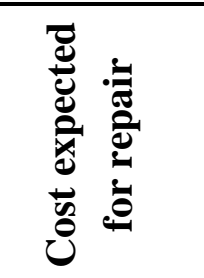 } & $<1$ million & 1 & \multirow{3}{*}{3} \\
\hline & $1-3$ million & 2 & \\
\hline & $>3$ million & 3 & \\
\hline \multicolumn{4}{|c|}{ Class V: Expected fire losses $\left(\psi_{f}=0.08\right)$} \\
\hline Parameter & Sub-parameter & $\begin{array}{c}\text { Weightage } \\
\text { factor }\left(\varphi_{f, x}\right)\end{array}$ & $\begin{array}{c}\text { Max. weightage } \\
\text { factor } \\
\left(\varphi_{f, x(\max )}\right)\end{array}$ \\
\hline \multirow{2}{*}{ 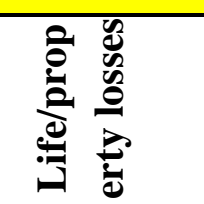 } & Minimum to no injuries & 1 & \multirow{2}{*}{3} \\
\hline & Minimum casualties & 2 & \\
\hline
\end{tabular}




\begin{tabular}{|c|c|c|c|}
\hline & Many casualties & 3 & \\
\hline \multirow{3}{*}{ 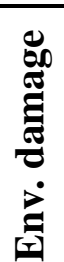 } & Minor damage & 1 & \multirow{3}{*}{3} \\
\hline & Significant damage & 2 & \\
\hline & Unacceptable damage & 3 & \\
\hline
\end{tabular}


Table 3 Risk grades and associated importance factors for fire design of bridges.

\begin{tabular}{|c|c|c|}
\hline Risk grade & $\begin{array}{c}\text { Overall class coefficient } \\
(\lambda)\end{array}$ & $\begin{array}{c}\text { Importance factor } \\
(\text { IF })\end{array}$ \\
\hline Critical & $\geq 0.95$ & 1.5 \\
\hline High & $0.50-0.95$ & 1.2 \\
\hline Medium & $0.20-0.49$ & 1.0 \\
\hline Low & $<0.20$ & 0.8 \\
\hline
\end{tabular}


Table 4 Proposed fire mitigation strategies and assigned weightage factors

\begin{tabular}{|c|c|c|c|}
\hline \multicolumn{4}{|c|}{ Class VI: Fire mitigation strategies } \\
\hline Parameter & Sub-parameter & $\begin{array}{c}\text { Weightage } \\
\text { factor } \\
\left(\varphi_{e, x}\right)\end{array}$ & $\begin{array}{c}\text { Max. weightage } \\
\text { factor } \\
\left(\varphi_{e, x(\max )}\right)\end{array}$ \\
\hline \multirow{4}{*}{ 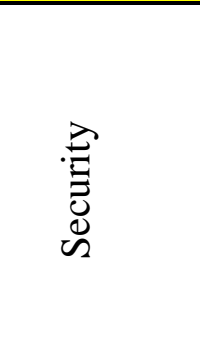 } & Monitoring systems & 1 & \multirow{4}{*}{4} \\
\hline & Guards & 2 & \\
\hline & Restricted access zones & 3 & \\
\hline & Fire detection systems & 4 & \\
\hline \multirow{4}{*}{ 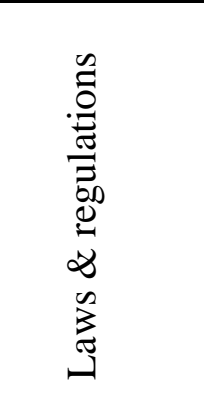 } & $\begin{array}{l}\text { Provide distinguished exits for large fuel } \\
\text { tankers }\end{array}$ & 1 & \multirow{4}{*}{4} \\
\hline & Limit operation timings & 2 & \\
\hline & Limit vehicle speed & 3 & \\
\hline & Limit transport size (20,000 liters) & 4 & \\
\hline \multirow{5}{*}{ 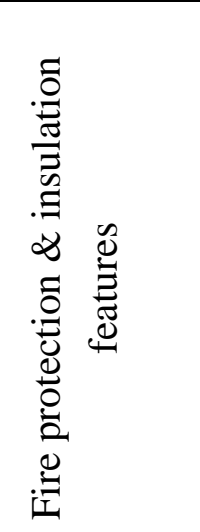 } & On site firefighting equipment & 1 & \multirow{5}{*}{5} \\
\hline & $\begin{array}{l}\text { Use of flooding agents and/or foam deluge } \\
\text { systems }\end{array}$ & 2 & \\
\hline & $1 \mathrm{hr}$ Insulation to main structural members & 3 & \\
\hline & $2 \mathrm{hr}$ Insulation to main structural members & 4 & \\
\hline & $\begin{array}{l}\text { Implementing structural fire design for } \\
\text { bridge }\end{array}$ & 5 & \\
\hline
\end{tabular}


Table 5 Fire risk categories descriptions and recommendations

\begin{tabular}{|c|c|l|c|}
\hline $\begin{array}{c}\text { Fire risk } \\
\text { category }\end{array}$ & $\begin{array}{c}\text { Importance } \\
\text { factor }\end{array}$ & \multicolumn{1}{|c|}{ Impact of fire on bridge } & $\begin{array}{c}\text { Recommended fire proofing } \\
\text { to structural members }\end{array}$ \\
\hline Low & 0.8 & $\begin{array}{l}\text { Negligible impact on integrity of bridge } \\
\text { or operation of facility, with no human } \\
\text { losses. }\end{array}$ & No need of fire proofing. \\
\hline Medium & 1.0 & $\begin{array}{l}\text { Minor impact on structural member of } \\
\text { bridge and operation with no human } \\
\text { losses. Some investments are necessary } \\
\text { to restore bridge following fire incident. }\end{array}$ & No need of fire proofing. \\
\hline High & 1.2 & $\begin{array}{l}\text { Significant impact on structural members } \\
\text { of bridge with partial/complete collapse } \\
\text { of main structural elements, partial } \\
\text { shutdown of operation with possible } \\
\text { human injuries/losses. }\end{array}$ & $\begin{array}{c}\text { At least one hour fire proofing } \\
\text { should be provided to main } \\
\text { structural elements. }\end{array}$ \\
\hline Critical & 1.5 & $\begin{array}{l}\text { Immediate/severe impact on bridge (loss } \\
\text { of carrying load capacity and total } \\
\text { collapse) and complete loss of operation. } \\
\text { Expected human casualties and } \\
\text { permanent closure of highway/bridge. }\end{array}$ & $\begin{array}{c}\text { One-to-two hour(s) fire } \\
\text { proofing should be provided } \\
\text { to main structural elements. }\end{array}$ \\
\hline
\end{tabular}




\section{LIST OF FIGURES}

Fig.1. Probability of fire occurrence and fire-induced collapse in buildings and bridges

Fig. 2. Contribution of different classes to importance factor

Fig. 3. Flow chart of the weightage factor approach for evaluating importance factor 


\section{Figures}

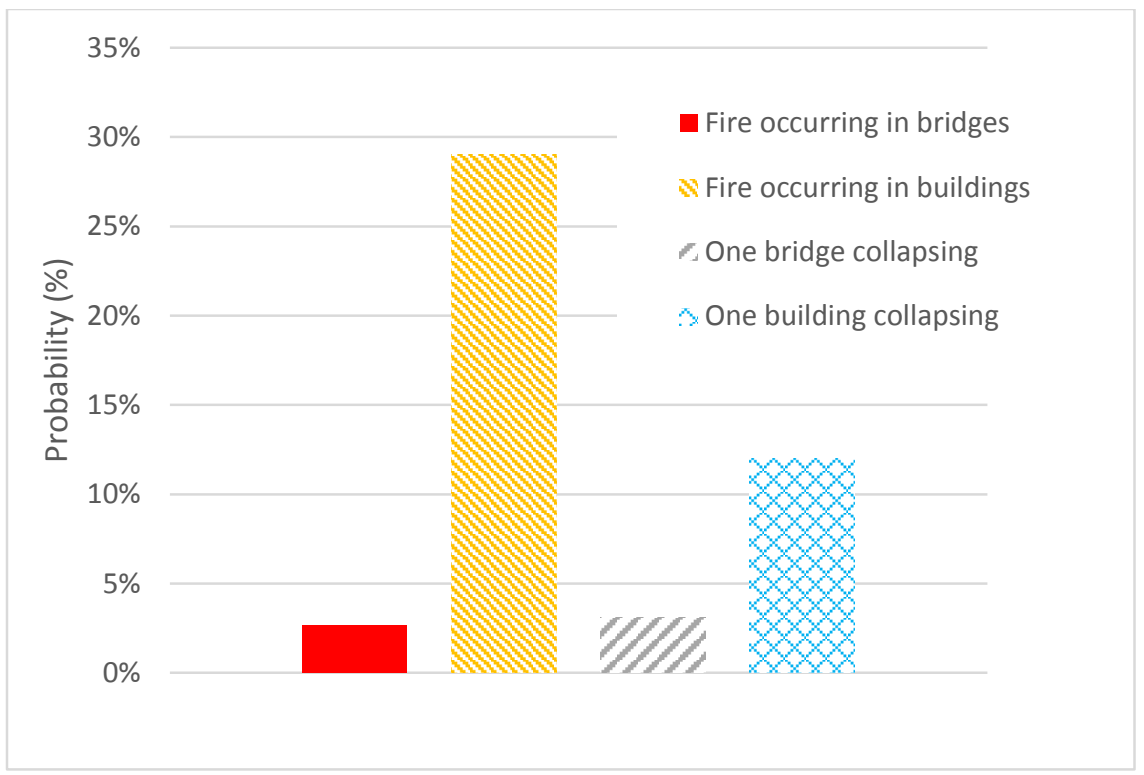

Fig.1. Probability of fire occurrence and fire-induced collapse in buildings and bridges 


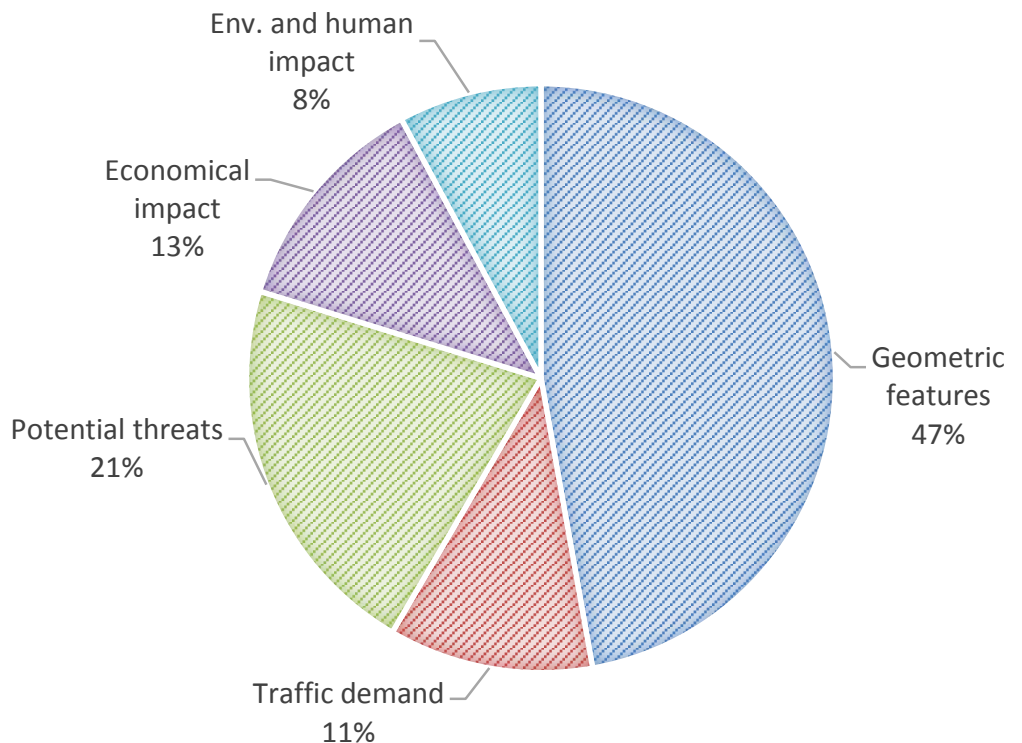

Fig. 2. Contribution of different classes to importance factor 


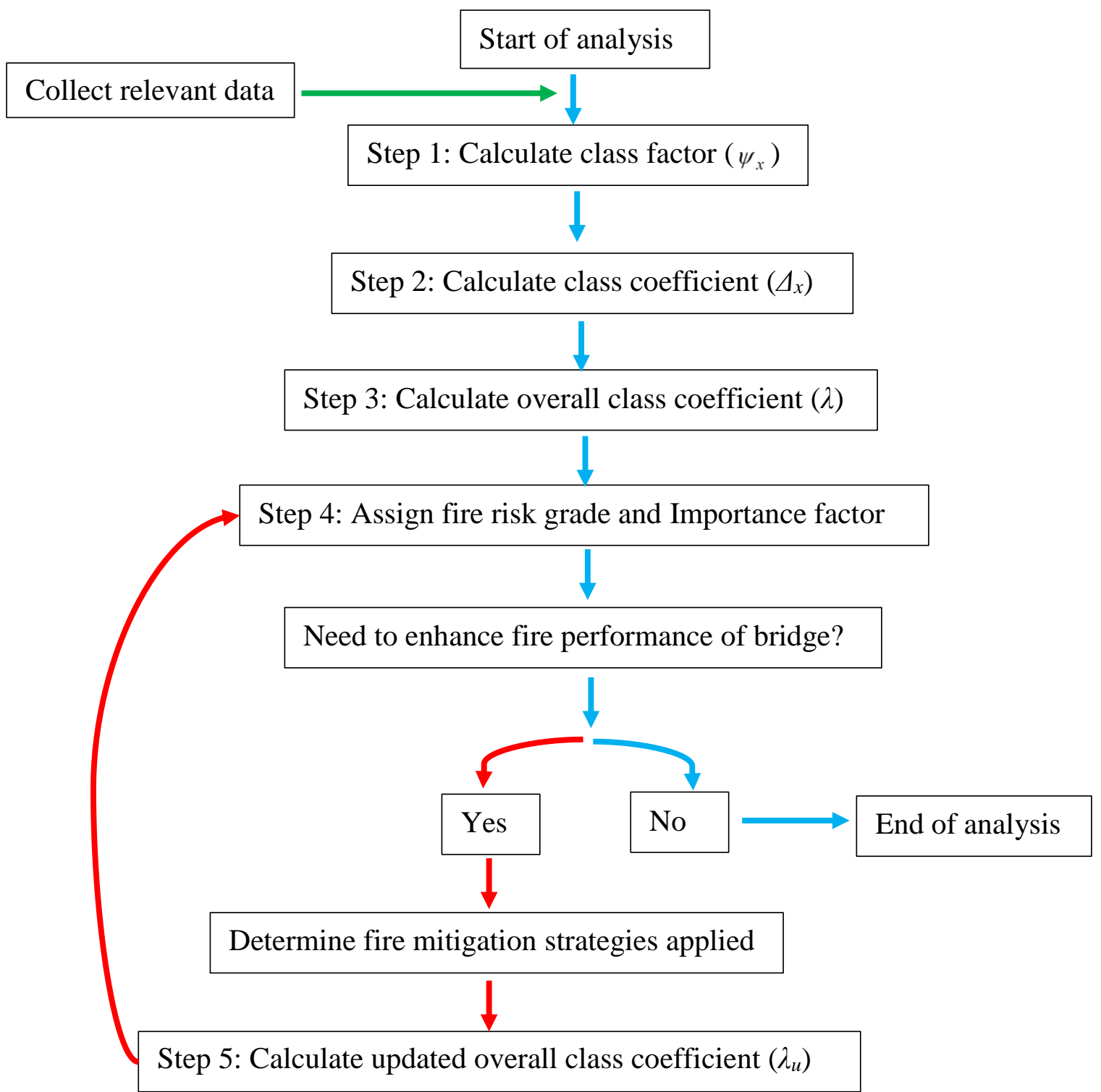

Fig. 3. Flow chart of the weightage factor approach for evaluating importance factor 